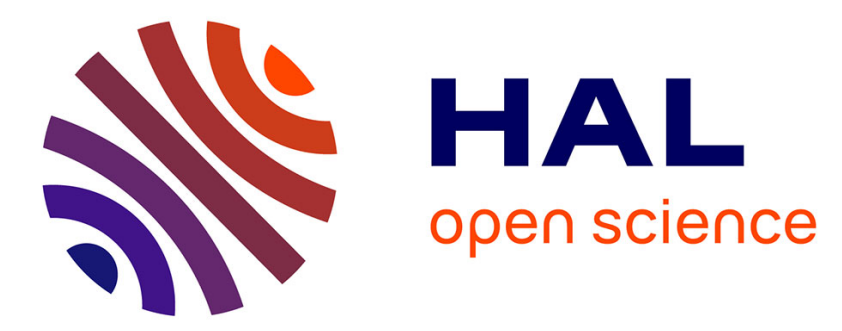

\title{
Volatile organic compounds absorption in packed column: theoretical assessment of water, DEHA and PDMS 50 as absorbents
}

Pierre-Francois Biard, Annabelle Couvert, Sylvain Giraudet

\section{To cite this version:}

Pierre-Francois Biard, Annabelle Couvert, Sylvain Giraudet. Volatile organic compounds absorption in packed column: theoretical assessment of water, DEHA and PDMS 50 as absorbents. Journal of Industrial and Engineering Chemistry, 2018, 59, pp.70-78. 10.1016/j.jiec.2017.10.008 . hal-01771099

HAL Id: hal-01771099

https://hal-univ-rennes1.archives-ouvertes.fr/hal-01771099

Submitted on 26 Apr 2018

HAL is a multi-disciplinary open access archive for the deposit and dissemination of scientific research documents, whether they are published or not. The documents may come from teaching and research institutions in France or abroad, or from public or private research centers.
L'archive ouverte pluridisciplinaire HAL, est destinée au dépôt et à la diffusion de documents scientifiques de niveau recherche, publiés ou non, émanant des établissements d'enseignement et de recherche français ou étrangers, des laboratoires publics ou privés. 


\section{Volatile organic compounds absorption in packed column: theoretical assessment of water, DEHA and PDMS 50 as absorbents}

Pierre-François BIARD ${ }^{\mathrm{a}}$, Annabelle COUVERT ${ }^{\mathrm{a}}$, Sylvain GIRAUDET ${ }^{\mathrm{a}}$

aÉcole Nationale Supérieure de Chimie de Rennes, CNRS, UMR 6226, 11 Allée de Beaulieu, CS 50837, 35708 Rennes Cedex 7, France

${ }^{*}$ Corresponding author : pierre-francois.biard@ensc-rennes.fr, +33 223238149

\section{Graphical abstract}

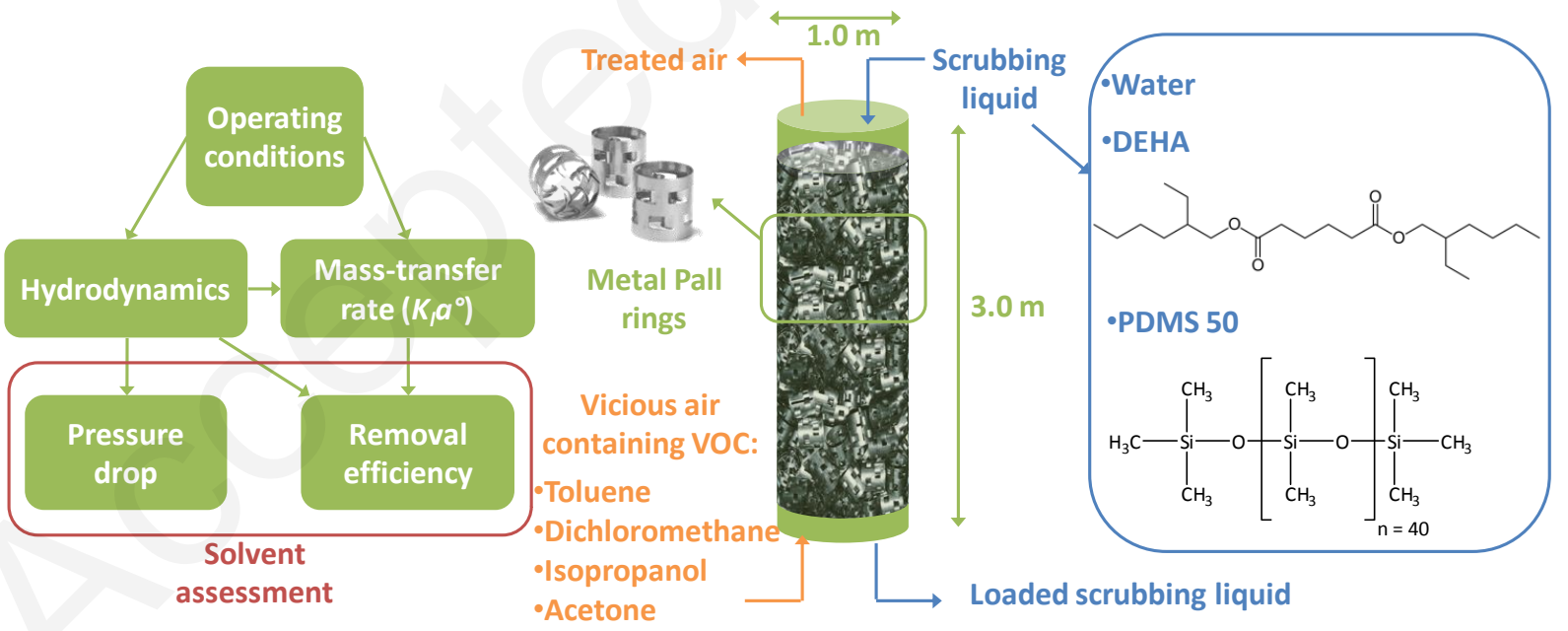




\title{
Highlights
}

- VOC absorption in water, DEHA and PDMS was simulated in a column of $2 \mathrm{~m}$ height

- The Billet-Schultes and Mackowiak theories were considered

- The pressure drop increased from 25\% (DEHA) and 45\% (PDMS) compared to water

- Hydrophobic compounds absorption in DEHA and PDMS was effective

- Some VOCs are hardly removed using DEHA and PDMS

\begin{abstract}
A fixed volume packed column was simulated for the absorption at counter-current of four more or less hydrophobic volatile organic compounds (VOCs) in water and in two heavy organic solvents (PDMS 50, a silicone oil) and DEHA (Bis(2-ethylhexyl) adipate)). Reliable values of the mass-transfer coefficients were deduced allowing to calculate the VOCs removal efficiency. Disappointing performances in heavy solvents, lower than $60 \%$ for isopropanol and acetone, were computed in a $3 \mathrm{~m}$ height column and using mild conditions (atmospheric pressure and a liquid-to-gas mass flow rate ratio around 2). However, toluene removal efficiencies higher than $90 \%$ were simulated.
\end{abstract}

\section{Keywords}

absorption; mass-transfer; volatile organic compound; DEHA; silicone oil; packed column

\section{Nomenclature}

$a^{\circ}$ : interfacial area relative to the packing volume $\left(\mathrm{m}^{2} \mathrm{~m}^{-3}\right)$

$A$ : absorption rate (dimensionless)

$A_{p}$ : packing specific surface area $\left(\mathrm{m}^{2} \mathrm{~m}^{-3}\right)$ 
ARE: average relative error

C: VOC concentration

$C_{l o}, C_{f l}, C_{h}, C_{p}, C_{L}, C_{G}$ : constants relative to each commercial packing according to Billet-Schultes [24]

$d_{h}$ : hydraulic diameter $(\mathrm{m})$

$d_{p}$ : packing size $(\mathrm{m})$

$d_{T}$ : mean droplet diameter $(\mathrm{m})$

$D_{\text {col: }}$ column diameter $(\mathrm{m})$

$D_{G}\left(D_{L}\right)$ : diffusion coefficient at infinite dilution of a solute in the gas phase (liquid phase) $\left(\mathrm{m}^{2} \mathrm{~s}^{-1}\right)$

Eff: removal efficiency

F: flow-rate $\left(\mathrm{m}^{3} \mathrm{~s}^{-1}\right.$ or $\mathrm{L} \mathrm{s}^{-1}$, often expressed in the normal conditions of temperature and pressure for a gas)

g: acceleration of gravity $\left(9.81 \mathrm{~m} \mathrm{~s}^{-2}\right)$

$h_{L}$ : liquid hold-up (dimensionless)

$H$ : Henry's law constant $\left(\mathrm{Pa} \mathrm{m} \mathrm{mol}^{-1}\right)$

$H T U_{O L}$ : overall height of a transfer unit in the liquid phase $(\mathrm{m})$

$k_{G}$ : gas-film mass-transfer coefficient $\left(\mathrm{m} \mathrm{s}^{-1}\right)$

$k_{L}$ : liquid-film mass-transfer coefficient $\left(\mathrm{m} \mathrm{s}^{-1}\right)$

$k_{G} a^{\circ}$ : local volumetric gas-side mass-transfer coefficient $\left(\mathrm{s}^{-1}\right)$

$k_{\llcorner} a^{\circ}$ : local volumetric liquid-side mass-transfer coefficient $\left(\mathrm{s}^{-1}\right)$

$K_{L} a^{\circ}$ : overall volumetric liquid-side mass-transfer coefficient $\left(\mathrm{s}^{-1}\right)$

$L / G$ : liquid-to-gas mass flow-rate ratio (dimensionless)

$N T U_{O L}:$ overall number of transfer units in the liquid phase

$P$ : absolute pressure in the reactor $(\mathrm{Pa})$

$R$ : ideal gas constant $\left(8.314 \mathrm{~J} \mathrm{~mol}^{-1} \mathrm{~K}^{-1}\right)$

$R_{L}$ : relative mass-transfer resistance in the liquid phase (\%)

$S_{\text {col: }}$ column section $\left(\mathrm{m}^{2}\right)$

$T$ : temperature of the contactor $\left({ }^{\circ} \mathrm{C}\right.$ or $\left.\mathrm{K}\right)$

$U:$ fluid velocity $\left(\mathrm{m} \mathrm{s}^{-1}\right)$

$U_{R}$ : relative phase velocity $\left(\mathrm{m} \mathrm{s}^{-1}\right)$

$Z$ : contactor or liquid height $(\mathrm{m})$

\section{Greek letters:}


$\varepsilon$ : void fraction (\%)

$\Delta P / z$ : linear pressure drop $(\mathrm{Pa})$

$\varphi_{p}$ : packing form factor (no unit)

$\mu_{L}$ : dynamic viscosity of the solvent (Pa s)

$\sigma_{L}$ : surface tension $\left(\mathrm{N} \mathrm{m}^{-1}\right)$

$\rho$ : density $\left(\mathrm{kg} \mathrm{m}^{-3}\right)$

$\psi$. resistance coefficient (no unit)

\section{Superscripts:}

eq: at the equilibrium

\section{Subscripts:}

fl: at the flooding point

G: relative to the gas

$\mathrm{i}$ : at the packing inlet

$\mathrm{L}$ : relative to the liquid

lo: at the loading point

$\mathrm{o}$ : at the packing outlet

$\mathrm{p}$ : relative to the packing

S: superficial (velocity)

\section{Introduction}

Due to its simplicity and its potential good efficiency, absorption in a packed column is an attractive gas cleaning technology for Volatile Organic Compounds (VOC) removal [1, 2]. Gaseous pollutants are transferred in a liquid phase which can be either aqueous (most of time) or organic. For hydrophobic neutral compounds, due to their poor affinity for water, absorption in aqueous solution is ineffective and 
organic solvents must be considered as an alternative [3]. Since the 2000's, a new generation of heavy organic solvent, such as phthalates, polydimethylsiloxane (PDMS, a silicone oil), Bis(2-ethylhexyl) adipate (DEHA) or ionic liquids drew a particular attention, especially for their good affinity with many VOC and low volatility, among other interesting characteristics [4-11]. However, their high viscosity can may hinder the mass-transfer in the liquid phase and increase the energy footprint through a higher pressure drop. Furthermore, the loading and flooding points, between which the packed column should be operated, can be significantly decreased [12].

Up to now, the assessment of such organic solvents for VOC absorption is often based only on the VOC/solvent affinity evaluation, through the gas-liquid partition coefficient measurement or Hansen parameter evaluation $[5,6,8-10,13,14]$. Dynamic absorption in lab-scale gas-liquid reactor provides additional information about the mass-transfer kinetics $[3,15]$. However, few studies confirmed the potential of these heavy solvents using realistic industrial gas-liquid contactors, especially packed columns $[12,16-19]$. Due to the high investment cost of such experimental devices, these experimental studies were limited to rather low column diameters $(<0.12 \mathrm{~m})$ and gas flow-rates $\left(<30 \mathrm{Nm}^{3} \mathrm{~h}^{-1}\right)$, in which wall-effects can be significant. They confirmed the feasibility of using packed column at the labscale but not at the industrial scale. For example, Guillerm et al. study (2016) showed that the high viscosity of PDMS 50, does not impede its use with both a random packing (IMTP ${ }^{\circledR}$ ) and a structured packing (Flexipac ${ }^{\circledR}$ ) possessing high void fractions (95 $\leq \varepsilon \leq 96 \%$ ) [12]. The pressure drops measured between the loading and flooding points were acceptable. Furthermore, these time-consuming studies were limited to the toluene absorption, which has a high affinity for both DEHA and PDMS. Nonetheless, many VOC have a lower affinity for these solvents $[3,10]$

To avoid costly industrial scale measurement campaigns, the potential of heavy solvents for the absorption in a packed column of different VOC could be advantageously assessed by simulations, which 
take into account the column hydrodynamics and mass-transfer rate. Thus, the goal of this study is to confirm the potential of DEHA and PDMS 50 for the absorption of four more or less hydrophobic VOC (toluene, which has an octanol-water partition coefficient $(\log P)=2.73$, dichloromethane $(D C M, \log P=$ 1.25), isopropanol $(\log P=0.25)$ and acetone $(\log P=-0.24)[20])$ in comparison with water. A realistic random packed column of $1 \mathrm{~m}$ diameter and $3 \mathrm{~m}$ height was considered for the treatment at atmospheric pressure and $20^{\circ} \mathrm{C}$ of a gas flow-rate of $4000 \mathrm{Nm}^{3} \mathrm{~h}^{-1}$ (where $\mathrm{N}$ stands for the standard temperature and pressure (STP) conditions, i.e. 1 bar and $0^{\circ} \mathrm{C}$ according to the IUPAC) at counter-current. PDMS 50, even being much more viscous than water, was selected because PDMS with lower viscosities (such as PDMS 5) are more volatile and emits VOC [13]. The fluid dynamics and mass-transfer rate were evaluated in the loading zone (i.e. between the loading and flooding points) where the performances of a packed column are optimal [21].

Besides the packing characteristics and some classic physico-chemical properties of the solvents such as their density, viscosity or surface tension, mass-transfer mainly depend on two parameters related to the VOC/solvents interactions : (i) the gas-liquid partition coefficient (i.e. gas-liquid equilibrium) and (ii) the VOC diffusion coefficient (which affects the mass-transfer in the liquid phase). The gas-liquid partition coefficients have been previously measured for the four VOC in the three considered solvents [3]. The diffusion coefficients measurement requires sophisticated techniques and equipments [7, 22, 23]. Nevertheless, their orders of magnitude in heavy solvents can be approached with the Scheibel and Wilke-Chang correlations with a sufficient level of confidence [3].

The absorption performances and the energy consumption of the simulated packed column were assessed respectively by the removal efficiency (Eff, Eq. 1$)$ and the linear pressure drop $\left(\Delta P / z\right.$ in Pa $\left.\mathrm{m}^{-1}\right)$. It required to determine previously the hydrodynamic characteristics (loading and flooding points, liquid 
hold-up and interfacial area) and mass-transfer characteristics (liquid and gas-side mass-transfer coefficients) [21]. Thus, different theories were considered and assessed.

\section{Theoretical background}

\subsection{Introduction}

A fixed volume packed column (1.0 m of internal diameter and $3.0 \mathrm{~m}$ of height), consisting of $35 \mathrm{~mm}$ metal Pall rings, was simulated for the absorption at counter-current of four VOC in water, DEHA and PDMS 50 (operating conditions and packing characteristics summarized in Tables 1 and 2). The gas-liquid partition coefficients and diffusion coefficients of this twelve solvent/solute couples have been already published in the article of Biard et al. (2016) [3], in which the physico-chemical properties of these VOC and solvents are summarized. A liquid-to-gas mass flow-rate ratio $(L / G)$ of nearly 2 was fixed using identical liquid and gas volume flow-rates $\left(F_{G}\right.$ and $\left.F_{L}\right)$ for the three solvents. Such value of $L / G$ is typical in packed columns since it ensures a good wetting of the packing with a moderate pressure drop.

The inlet gas concentration was not considered in the computations since it is uninfluential unless it exceeds a limit leading to a significant deviation to the assumption of a infinitely low concentration in the liquid phase. This assumption is necessary for the use of the liquid diffusion coefficient calculated at infinite dilution and of the Henry's law constants as partition coefficients. This consideration is realistic for VOC treatment which usually involves low concentrations $(<5000$ ppmv). The operation was considered as isotherm (the fluids were considered introduced at $20^{\circ} \mathrm{C}$ ) and isobar (the pressure drop is negligible).

Table 1: Operating conditions simulated.

$\begin{array}{ccccccccccc}D_{c o l} & Z & P & T & F_{G} & F_{L} & L / G & L / G & L / G & U_{S G} & U_{S L} \\ (\mathrm{~m}) & (\mathrm{m}) & (\text { bar }) & (\mathrm{K}) & \left(\mathrm{Nm}^{3} \mathrm{~h}^{-1}\right) & \left(\mathrm{m}^{3} \mathrm{~h}^{-1}\right) & \text { water } & \text { DEHA } & \text { PDMS } & \left(\mathrm{m} \mathrm{s}^{-1}\right) & \left(\mathrm{mm} \mathrm{s}^{-1}\right)\end{array}$




\begin{tabular}{|lllllllllll|}
\hline 1.0 & 3.0 & 1 & 293 & 4000 & 11.0 & 2.13 & 1.96 & 2.04 & 1.52 & 3.9 \\
\hline
\end{tabular}

Table 2: Characteristics of the 35 metal Pall rings selected. The last six columns correspond to the constants specific to this packing determined by Billet et al [24].

\begin{tabular}{lccccccccccc|}
$d_{p}(m)$ & $A_{p}\left(m^{2} m^{-3}\right)$ & $\varepsilon$ & $\sigma_{p}(N / m)$ & $d_{h}(m)$ & $\varphi_{p}$ & $C_{l o}$ & $C_{f 1}$ & $C_{h}$ & $C_{p}$ & $C_{L}$ & $C_{V}$ \\
0.035 & 139.4 & 0.965 & 0.071 & 0.0277 & 0.28 & 2.629 & 1.679 & 0.644 & 1.003 & 1.277 & 0.341 \\
\hline
\end{tabular}

\subsection{Removal efficiency determination}

The removal efficiency, defined by Eq. 1, was considered as the main performance indicator to assess the potential of the three solvents:

$E f f=\frac{C_{G, i}-C_{G, o}}{C_{G, i}}$

Eq. 1.

Where $C_{G, i}$ and $C_{G, O}$ are the VOC concentrations in the gas at respectively the inlet and the outlet of the packing. Assuming isothermal liquid and gas plug flows at counter-current, the removal efficiency (Eff) obtained for a given column height $(Z$ in $\mathrm{m})$ is deduced by the following equation [25]:

$E f f=\frac{A\left(1-\exp \left((1-A) N T U_{O L}\right)\right)}{A-\exp \left((1-A) N T U_{O L}\right)}$ withNTU $_{O L}=\frac{Z}{H T U_{O L}}$ and $H T U_{O L}=\frac{F_{L}}{K_{L} a^{\circ} S_{c o l}}$

Eq. 2.

$N T U_{O L}$ (no unit) and $H T U_{O L}(\mathrm{~m})$ are respectively the overall Number and Height of a Transfer Unit in the liquid phase. $F_{L}$ is the liquid flow-rate $\left(\mathrm{m}^{3} \mathrm{~s}^{-1}\right), S_{c o l}$ is the column diameter $\left(\mathrm{m}^{2}\right)$ and $A$ is the absorption rate (dimensionless):

$A=\frac{R T F_{L}}{H F_{G}}$

Eq. 3. 
$K_{L} a^{\circ}$ is the overall volumetric liquid-phase mass-transfer coefficient $\left(\mathrm{s}^{-1}\right)$ which is related to the gas and liquid-side coefficients $\left(k_{G}\right.$ and $k_{L}$ in $\left.\mathrm{m} \mathrm{s}^{-1}\right)$, the interfacial area $\left(a^{\circ}\right.$ in s$\left.{ }^{-1}\right)$ and the Henry's law constant $(H$ in $\left.\mathrm{Pa} \mathrm{m} \mathrm{mol}^{-1}\right)$ :

$\frac{1}{K_{L} a^{\circ}}=\frac{1}{k_{L} a^{\circ}}+\frac{R T}{H k_{G} a^{\circ}}$

Eq. 4.

The local volumetric mass-transfer coefficients $\left(k_{L} a^{\circ}\right.$ and $k_{G} a^{\circ}$ in $\left.\mathrm{s}^{-1}\right)$ can be calculated according to different theories (section 2.4) for random packings [21, 24-28]. A hydrodynamic study is previously necessary (section 2.3) to determine the loading and flooding points, between which the systems should be operated, the interfacial area $\left(a^{\circ}\right)$ and the liquid hold-up $\left(h_{L}\right)$. The loading and flooding points correspond to the gas superficial velocity $\left(U_{S G}\right.$ in $\left.\mathrm{m} \mathrm{s}^{-1}\right)$ values for which the liquid starts to load or flood the packing for a fixed $L / G$ ratio [21].

\subsection{Hydrodynamics in a packed column}

The correlations of Billet-Schultes have been introduced in the nineties to determine the loading and flooding points, liquid hold-up, pressure drop and interfacial area using old and new generation packings [24, 29-31]. They have been developed for several different packings and for a wide range of physicochemical properties, especially liquids with kinematic viscosities $\left(\mu_{L} / \rho_{L}\right)$ up to 100 or $142 \times 10^{-6} \mathrm{~m}^{2} \mathrm{~s}^{-1}$ (depending on the determined variable), which includes heavy solvents such as PDMS 50 or DEHA [24]. According to Heymes et al. (2006), these correlations are accurate to determine the loading and flooding gas superficial velocities as well as the pressure drop using DEHA [17]. This theory requires to use several constants specific to each commercial packing (Table 2 for metal Pall rings). The superficial gas and liquid velocities at the loading point $\left(U_{S G, 10}\right.$ and $\left.U_{S L, 10}\right)$ were deduced from Eqs. 4 and 5 [30]:

$U_{S G, 10}=\sqrt{\frac{g}{\psi_{10}}}\left(\varepsilon-h_{L, 10}\right) \sqrt{\frac{h_{L, I 0}}{A_{p}}} \sqrt{\frac{\rho_{L}}{\rho_{G}}}$

Eq. 5. 
$U_{S L, I o}=\frac{\rho_{G}}{\rho_{L}} \frac{L}{G} U_{S G, l o}$

Eq. 6.

$\varepsilon$ and $A_{p}\left(\mathrm{~m}^{2} \mathrm{~m}^{-3}\right)$ are respectively the void fraction and the packing specific surface area. $\rho_{\llcorner}\left(\rho_{G}\right)$ is the liquid (gas) density $\left(\mathrm{kg} \mathrm{m}^{-3}\right) . \psi_{10}$, the resistance coefficient at the loading point, can be calculated for $\frac{L}{G} \sqrt{\frac{\rho_{G}}{\rho_{L}}}<0.4$ by Eq. $7\left(\frac{L}{G} \sqrt{\frac{\rho_{G}}{\rho_{L}}} \approx 0.07-0.08\right.$ inthisstudy $):$

$\psi_{l o}=\frac{g}{C_{l o}^{2}}\left(\frac{L}{G} \sqrt{\frac{\rho_{G}}{\rho_{L}}}\left(\frac{\mu_{L}}{\mu_{G}}\right)^{0.4}\right)^{2 \times 0.326}$

Eq. 7.

$\mu_{\llcorner}\left(\mu_{G}\right)$ is the liquid (gas) dynamic viscosity (Pa s). $h_{L, 10}$ is the liquid hold-up at the loading point calculated by Eq. 8 [24]:

$h_{L, 10}=\left(\frac{12}{g} \frac{\mu_{L}}{\rho_{L}} U_{S L, I O} A_{p}^{2}\right)^{1 / 3}\left(\frac{a_{h}}{A_{p}}\right)_{10}^{2 / 3}$

Eq. 8.

$\left(a_{h} / A_{p}\right)_{10}$ is the ratio of the hydraulic to geometric surface area at the loading point, which is calculated for a Reynolds Number of the liquid at the loading point $\left(R e_{L, 10}\right)$ lower than 5 by Eq. $9\left(R e_{L, 10}=2.59\right.$ for water, 1.61 for DEHA, 0.40 for PDMS 50) [30]:

$\left(\frac{a_{h}}{A_{p}}\right)_{10}=C_{h} \operatorname{Re}_{L, I 0}^{0.15}\left(\frac{U_{S L, I 0}{ }^{2} A_{p}}{g}\right)^{0.1}$

Eq. 9.

$R e_{L, l o}$ corresponds to $R e_{L}$ calculated at the loading point:

$\operatorname{Re}_{L, / o}=\frac{U_{S L, I o} \rho_{L}}{A_{p} \mu_{L}}$

Eq. 10.

The superficial gas velocity at the flooding point $\left(U_{S G, f l}\right)$ is deduced from Eq. 11 [31]: 
$U_{S G, f l}=\sqrt{\frac{2 g}{\psi_{f l}} \frac{\left(\varepsilon-h_{L, f l}\right)^{3 / 2}}{\varepsilon^{1 / 2}}} \sqrt{\frac{h_{L, f l}}{A_{p}}} \sqrt{\frac{\rho_{L}}{\rho_{G}}}$

Eq. 11.

$\psi_{f l}$, the resistance coefficient at the flooding point, can be calculated for $\frac{L}{G} \sqrt{\frac{\rho_{G}}{\rho_{L}}}<0.4$ according to Eq.

12:

$\psi_{f l}=\frac{g}{C_{f l}^{2}}\left(\frac{L}{G} \sqrt{\frac{\rho_{G}}{\rho_{L}}}\left(\frac{\mu_{L}}{\mu_{G}}\right)^{0.2}\right)^{2 \times 0.194}$

Eq. 12.

$h_{L, f l}$ is the liquid hold-up at the flooding point calculated by Eq. 13 [31]:

$h_{L, f l}^{3}\left(3 h_{L, f l}-\varepsilon\right)=\frac{6}{9} A_{p}^{2} \varepsilon \frac{\mu_{L}}{\rho_{L}} \frac{L}{G} \frac{\rho_{G}}{\rho_{L}} U_{S G, f l}$

Eq. 13.

The systems of equations $5-10$ and $11-13$ were solved by numerical resolution for each solvent considered to determine respectively $U_{S G, l o}$ and $U_{S G, f l}$.

The selection of a working gas superficial velocity $\left(U_{S G}\right)$ between the loading and flooding points (typically at $60-80 \%$ of the flooding point) is recommended [25]. Then, the column diameter is usually deduced from the gas flow-rate $F_{G}$ and the selected value of $U_{S G}$. In order to compare the different solvents with the same column diameter and $U_{S G}$, the column diameter $\left(D_{c o l}\right)$ was set to $1 \mathrm{~m}\left(U_{S G}=1.52 \mathrm{~m} \mathrm{~s}^{-1}\right)$ but the ratio $U_{S G} / U_{S G, f l}$ was adapted for each solvent. The liquid hold-up $\left(h_{L}\right)$ and the linear pressure drop $(\Delta P / z$ in $\mathrm{Pa} \mathrm{m}^{-1}$ ) at the working point were finally deduced respectively by Eqs. 14 and 15 [24, 28-30]:

$$
\begin{aligned}
& h_{L}=\left(\frac{12}{g} \frac{\mu_{L}}{\rho_{L}} U_{S L, I O} A_{p}^{2}\right)^{1 / 3}+\left(h_{L, f l}-\left(\frac{12}{g} \frac{\mu_{L}}{\rho_{L}} U_{S L, I O} A_{p}^{2}\right)^{1 / 3}\right)\left(\frac{U_{S G}}{U_{S G, f l}}\right)^{13} \\
& \frac{\Delta P}{z}=C_{P}\left(\frac{64}{\operatorname{Re}_{G}}+\frac{1.8}{\operatorname{Re}_{G}{ }^{0.08}}\right)\left(\frac{\varepsilon-h_{L}}{\varepsilon}\right)^{1.5}\left(\frac{h_{L}}{h_{L, f l}}\right)^{0.3} \frac{\rho_{G} U_{S G}{ }^{2}}{2}\left(1+\frac{4}{A_{p} D}\right)
\end{aligned}
$$

Eq. 15. 
$R e_{G}$ is a modified gas Reynolds number calculated at the working point:

$\operatorname{Re}_{G}=\frac{6 U_{S G} \rho_{G}}{A_{p} \mu_{G}}\left(1+\frac{4}{A_{p} D_{\text {col }}}\right)^{-1}=4250$

Eq. 16.

\subsection{Mass-transfer in a packed column}

\subsubsection{Billet et Schultes theory}

Three theories have been considered for the calculation of the volumetric gas and liquid-film masstransfer coefficients $\left(k_{L} a^{\circ}\right.$ and $\left.k_{G} a^{\circ}\right)$. According to Billet and Schultes, $k_{L} a^{\circ}$ and $k_{G} a^{\circ}$ can be respectively calculated according to the following relations [24, 28]:

$k_{L} a^{\circ}=C_{L} 12^{1 / 6}\left(\frac{U_{S L}}{h_{L}}\right)^{1 / 2}\left(\frac{D_{L}}{d_{h}}\right)^{1 / 2} a^{\circ}$

Eq. 17.

$k_{G} a^{\circ}=C_{G} \frac{1}{\left(\varepsilon-h_{L}\right)^{1 / 2}} \frac{A_{p}^{1 / 2}}{d_{h}{ }^{1 / 2}} D_{G}\left(\frac{\rho_{G} U_{S G}}{A_{p} \mu_{G}}\right)^{3 / 4}\left(\frac{\mu_{G}}{\rho_{G} D_{G}}\right)^{1 / 3} a^{\circ}$

Eq. 18.

With $a^{\circ}$ the interfacial area determined separately:

$a^{\circ}=1.5 A_{p}^{1 / 2} d_{h}{ }^{-1 / 2}\left(\frac{\rho_{L} U_{S L} d_{h}}{\mu_{L}}\right)^{-0.2}\left(\frac{\rho_{L} U_{S L}{ }^{2} d_{h}}{\sigma_{L}}\right)^{0.75}\left(\frac{U_{S L}{ }^{2}}{d_{h} g}\right)^{-0.45}$

And $d_{h}$ the hydraulic diameter $(\mathrm{m})$ :

$d_{h}=\frac{4 \varepsilon}{A_{p}}$

Eq. 20.

Contrarily to the hydrodynamic variables (section 2.3), the correlations 17-19 were developed for a kinematic viscosity lower than $1.66 \times 10^{-6} \mathrm{~m}^{2} \mathrm{~s}^{-1}$ which don't include PDMS 50 and DEHA [24]. On the one hand, it might be problematic for the calculation of $a^{\circ}$ (Eq. 19) which depends significantly on the 
viscosity. On the other hand, $k_{L}$ and $k_{G}$ (Eqs 17 and 18 ) does not depend on the viscosity. Nonetheless, the viscosity can affect indirectly $k_{L}$ through the diffusion coefficient in the liquid phase $\left(D_{L}\right)$. Fortunately, the diffusion coefficients range covered by the Billet-Schultes theory $\left(2.9-65 \times 10^{-10} \mathrm{~m}^{2} \mathrm{~s}^{-1}\right)$ was just slightly higher than the one predicted for DEHA and PDMS $\left(1.40-2.71 \times 10^{-10} \mathrm{~m}^{2} \mathrm{~s}^{-1}\right)$ using the Wilke-Chang correlation $[3,24]$. Therefore, $k_{L}$ values in DEHA and PDMS 50 should be estimated with a rather high confidence level by Eq. 17.

\subsubsection{Mackowiak theory}

According to Mackowiak, between the loading and flooding points, both $k_{\llcorner} a^{\circ}$ and $k_{G} a^{\circ}$ can be deduced by the equations $21-25[32,33]$. For a laminar liquid flow $\left(R e_{L}<2\right)$, which includes DEHA and PDMS 50, $k_{L} a^{\circ}$ is deduced from 21:

$k_{L} a^{\circ}=\frac{15.1}{\left(1-\varphi_{P}\right)^{1 / 3} d_{h}{ }^{1 / 4}}\left(\frac{D_{L}\left(\rho_{L}-\rho_{G}\right) g}{\sigma_{L}}\right)^{1 / 2}\left(\frac{A_{P}}{g}\right)^{1 / 6}\left(0.35+\frac{U_{S G}}{U_{S G, f l}}\right) U_{S L}{ }^{5 / 6}$

For a turbulent liquid flow $\left(\operatorname{Re}_{L} \geq 2\right)$, which includes water, $k_{L} a^{\circ}$ is deduced from 22 :

$k_{L} a^{\circ}=\frac{17.3 A_{P}^{1 / 3}}{\left(1-\varphi_{P}\right)^{1 / 3} d_{h}^{1 / 4}}\left(\frac{D_{L}\left(\rho_{L}-\rho_{G}\right) g}{\sigma_{L}}\right)^{1 / 2}\left(3 \frac{\mu_{L}}{g \rho_{L}}\right)^{1 / 6} U_{S L}^{2 / 3}$

For $400<R e_{G}<17500$, with $\operatorname{Re}_{G}$ calculated by Eq. $16, k_{G} a^{\circ}$ is deduced from 23 :

$k_{G} a^{\circ}=6 \frac{h_{L}}{d_{T}{ }^{2}} D_{G}\left(2+0.0285 \frac{U_{R} d_{T} \rho_{G}}{\mu_{G}}\left(\frac{\mu_{G}}{\rho_{G} D_{G}}\right)^{1 / 3}\right)\left(1-\frac{h_{L}}{\varepsilon}\right)^{6}$

With $d_{T}$ the mean droplet diameter $(\mathrm{m})$ according to Sauter $[32,33]$ :

$d_{T}=\sqrt{\frac{\sigma_{L}}{\left(\left(\rho_{L}-\rho_{G}\right) g\right)}}$ for $\sigma_{L} \geq 15 \mathrm{mN} \mathrm{m}^{-1}$

Eq. 24. 
$u_{R}$ is the relative phase velocity:

$u_{R}=\frac{u_{S G}}{\varepsilon-h_{L}}+\frac{u_{S L}}{h_{L}}$

Eq. 25.

And $\varphi_{p}$ the packing form factor ( $=0.28$ for the $35 \mathrm{~mm}$ metal Pall rings packing). Contrarily to the Billet-

Schultes theory (Eq. 19), the Mackowiak theory does not allow to calculate separately the interfacial area $\left(a^{\circ}\right)$.

\subsubsection{Piché et al. theory}

At the beginning of the 2000's, Piché et al. developed seven correlations based on neural networks to determine the loading and flooding points, the hold-up, the pressure drop, the interfacial area and both the liquid and gas-film mass-transfer coefficients [26, 27, 34-37]. They depend on a massive number of characteristic dimensionless numbers of both phases (Froude, Weber, Reynolds, Schmidt, etc.). The authors developed a free to use spreadsheet available online to calculate each of this parameter according to the entered operating conditions.

\section{Results and discussion}

\subsection{Packed column hydrodynamics}

Table 3: Determination of the loading and flooding points, liquid hold-up, the linear pressure drop and the interfacial area. Except for the interfacial area, the theory of Billet-Schultes was used (section

2.3).

\begin{tabular}{ccccccccccc}
\hline Solvant & $\begin{array}{c}\mu \mu \\
(\mathrm{mPa} \mathrm{s})\end{array}$ & $\begin{array}{c}U_{s G, l o} \\
\left(\mathrm{~m} \mathrm{~s}^{-1}\right)\end{array}$ & $\begin{array}{c}U_{s G, f l} \\
\left(\mathrm{~m} \mathrm{~s}^{-1}\right)\end{array}$ & $U_{s G / U_{s G, f l}}$ & $\begin{array}{c}h_{L} \\
(\%)\end{array}$ & $\begin{array}{c}\Delta P / 2 \\
\left(\mathrm{~Pa} \mathrm{~m}^{-1}\right)\end{array}$ & $\begin{array}{c}\text { Piché } \\
\text { et al. }\end{array}$ & $\begin{array}{c}\text { Billet- } \\
\text { Schultes }\end{array}$ & Onda \\
Water & 1.0 & 1.41 & 2.45 & 0.62 & 4.5 & 288 & 72.2 & 70.3 & 78.2 \\
DEHA & 12.5 & 1.19 & 2.14 & 0.71 & 10.2 & 360 & 64.6 & $>\mathrm{A}_{p}$ & 105.2 \\
PDMS & 50.0 & 1.14 & 2.03 & 0.75 & 15.8 & 416 & 61.0 & $>A_{p}$ & 116.6 \\
\hline
\end{tabular}




\subsubsection{Determination of the loading zone, the liquid hold-up and the pressure drop}

Using the Billet-Schultes theory (Eqs 5-10 and 11-13), the loading and flooding velocities $\left(U_{S G, 10}\right.$ and $\left.U_{S G, f l}\right)$ decreased for increasing solvent viscosities (Table 3) in agreement with the experimental observations of several studies $[12,16,17]$. Therefore, to respect the constraint of a constant column diameter of $1 \mathrm{~m}$, the selection of slightly higher $U_{S G} / U_{S G, f l}$ ratios was necessary for DEHA and PDMS. According to Heymes et al. (2006), the pressure drop, liquid hold-up and loading zone using DEHA were fairly estimated by the correlations of Billet-Schultes (section 2.3) [17]. Furthermore, Guillerm et al. (2016) determined the loading and flooding velocities evolution with the liquid flow rate for two random packings (15 $\mathrm{mm}$ glass Raschig rings and $15 \mathrm{~mm}$ metal IMTP ${ }^{\circledR}$ saddles) and in one structured packing (Flexipac ${ }^{\circledR} 500 \mathrm{HC}$ ) using PDMS 50 [12]. However, these three packing have not been characterized by Billet and Schultes (i.e. $C_{10}$, $\mathrm{C}_{\mathrm{fl}}, \mathrm{C}_{\mathrm{h}}$ are unknown). Therefore, it was not possible to control the reliability of the results regarding this theory. They measured low and disappointing loading and flooding velocities using the Raschig rings because the high PDMS 50 viscosity was not adapted to the low void fraction of this dumped packing (82.0\%). Nonetheless, the loading and flooding velocities obtained with IMTP $^{\circledR}$ and Flexipac ${ }^{\circledR}$ packings were satisfactory. These two packings have similar void fraction (respectively $96 \%$ and $95 \%$ ), close to the one of the $35 \mathrm{~mm}$ Pall rings selected in this analysis. At the same $U_{S L}$ than the one simulated in this study (3.9 $\mathrm{mm} \mathrm{s}^{-1}$ ), the measured loading (between 1.0 and $1.1 \mathrm{~m} \mathrm{~s}^{-1}$ depending on the packing) and flooding (between 1.4 and $1.5 \mathrm{~m} \mathrm{~s}^{-1}$ depending on the packing) velocities were in a good agreement with the one summarized Table 3.

The Piché et al. correlations have been also used to determine the loading and flooding velocities [35, 36]. Even if the DEHA and PDMS 50 physico-chemical properties matched the range covered by this theory for the correlation development, the velocities found were surprisingly very high (loading velocities around $2.7 \mathrm{~m} \mathrm{~s}^{-1}$ whatever the liquid considered). Furthermore, this theory was also applied to 
the experimental conditions of Heymes el al. (2006) and a severe deviation has been noticed between the prediction of the model and the experimental results [17]. It should be stressed that this correlation was further validated using a narrow validation database which includes only water using Hiflow $^{\circledR}$ rings and Novalox ${ }^{\circledR}$ saddles. Therefore, only the theory of Billet-Schultes was considered for the loading zones determination.

The DEHA and PDMS 50 higher viscosities leaded to a liquid hold-up respectively twice and three-times higher. Due to the high sensitivity of the pressure drop to the liquid hold-up, $\Delta P / Z$ increased by approximately $25 \%$ and $45 \%$ for respectively DEHA and PDMS compared to water, which might be reasonable regarding the high mass-transfer improvement expected with these solvents. These results are in agreement with the pressure drop increasing of 30\% observed by Heymes et al. (2006) using DEHA in Hiflow ${ }^{\circledR}$ rings [17].

\subsubsection{Determination of the interfacial area}

Using Eq. 19 (Billet-Schultes), unrealistic and unachievable values of the DEHA and PDMS 50 interfacial area (even at the loading point), higher than the specific surface of the packing, have been calculated. Contrarily to the correlations used in the section 3.1.1, Eq. 19 was established using a narrow liquid kinematic viscosity range $\left(0.14-1.66 \mathrm{~m}^{2} \mathrm{~s}^{-1}\right)$, which includes water but not DEHA and PDMS 50 [28, 31]. Eq. 19 is a power law function of the Reynolds number relative to $d_{h}$ $\left(\frac{\rho_{L} U_{S L} d_{h}}{\mu_{L}}=99.9\right.$ for water,6.21for DEHA, 1.56for PDMS 50), which is inversely proportional to the liquid viscosity. A very high sensitivity of the interfacial area to the Reynolds number is observed, which can lead to severe deviations. The interfacial area was unfortunately not measured in the experimental studies focused on the toluene absorption in heavy solvents using random packings, which do not allow a comprehensive comparison to experimental data $[12,16,17]$. Alternatively, the interfacial area has 
been calculated using the well-known equation of Onda et al. (Table 3) [25, 38], which is less sensitive to the viscosity, and the Piché et al. correlation (2001) [27]:

$$
\frac{a^{\circ}}{A_{p}}=1-\exp \left[-1.45\left(\frac{\sigma_{p}}{\sigma_{L}}\right)^{0.75}\left(A_{p} d_{p}\right)^{-0.35}\left(\frac{g d_{p}^{3} \rho_{L}^{2}}{\mu_{L}^{2}}\right)^{0.05}\left(\frac{d_{p} \rho_{L} U_{S L}{ }^{2}}{\sigma_{L}}\right)^{0.2}\right] \quad \text { Eq. } 26 .
$$

A good agreement between the three methods was obtained for water (relative deviation of $8 \%$ between Onda and Billet-Schultes, $2.7 \%$ between Piché et al. and Billet-Schultes). One the one hand, DEHA and PDMS 50 interfacial areas calculated by Eq. 26 are consistent but are surprisingly larger than the water interfacial area. According to Piché et al.(2001), an increasing of the interfacial area is expected from a decreasing of the viscosity and an increasing of the surface tension [27]. Such a sharp increasing of the interfacial area regarding the high DEHA and PDMS 50 viscosities is undesirable. On the other hand, the Piché et al. correlation for $a^{\circ}$ calculation, covers liquid viscosities up to $26 \times 10^{-3}$ Pa $\mathrm{S}$, including DEHA and approaching PDMS 50. Thus, on the contrary of the Onda correlation (Eq. 26), this correlation predicts a moderate decreasing of the DEHA (by 11\%) and PDMS 50 (by 16\%) interfacial areas, by comparison to water, which is more likely. This decreasing, expected according to the high PDMS 50 and DEHA viscosities, is counterbalanced by their low surface tension (DEHA: $31.0 \mathrm{mN} \mathrm{m}^{-1}$, PDMS $50: 20.8 \mathrm{mN} \mathrm{m}^{-1}$ ). Therefore, Piché et al. correlation should provide a fairly estimation of the true DEHA and PDMS 50 interfacial area, which will be coupled to the values of $k_{L}$ and $k_{G}$ determined by the Billet-Schultes theory in the next section (3.2).

\subsection{Mass-transfer in the packed column}

Table 4: Mass-transfer coefficients and $\boldsymbol{R}_{L}$ values according to the Billet-Schultes and Mackowiak theories using water. 


\begin{tabular}{|c|c|c|c|c|c|c|c|c|c|c|c|c|}
\hline \multirow[b]{3}{*}{ VOC } & \multicolumn{2}{|c|}{ Properties } & \multicolumn{5}{|c|}{ Billet-Schultes theory } & \multicolumn{5}{|c|}{ Mackowiak theory } \\
\hline & $H$ & $\begin{array}{c}10^{10 x} \\
D_{L}\end{array}$ & $\begin{array}{c}10^{4} x \\
k_{L}\end{array}$ & $\begin{array}{c}10^{2} \times k \\
G\end{array}$ & $\begin{array}{c}10^{3} \times K_{L} \\
a^{0}\end{array}$ & $R_{L}$ & $\begin{array}{c}\text { HUT } \\
\text { OL }\end{array}$ & $\begin{array}{c}10^{3} \times k_{L} \\
a^{\circ}\end{array}$ & $\begin{array}{c}k_{G} a \\
\circ\end{array}$ & $\begin{array}{c}10^{3} \times K_{L} \\
a^{0}\end{array}$ & $R_{L}$ & $\begin{array}{c}H U T \\
\text { OL }\end{array}$ \\
\hline & $\begin{array}{l}\mathrm{Pa} \\
\mathrm{m}^{3} \\
\mathrm{~mol}_{-1}\end{array}$ & $\mathrm{~m}^{2} \mathrm{~s}^{-1}$ & $\mathrm{~m} \mathrm{~s}^{-1}$ & $\mathrm{~m} \mathrm{~s}^{-1}$ & $\mathrm{~s}^{-1}$ & $\%$ & $\mathrm{~m}$ & $\mathrm{~s}^{-1}$ & $\mathrm{~s}^{-1}$ & $\mathrm{~s}^{-1}$ & $\%$ & $\mathrm{~m}$ \\
\hline $\begin{array}{c}\text { Toluen } \\
\text { e }\end{array}$ & 510 & 7.96 & 0.967 & 3.31 & 6.70 & $\begin{array}{c}98 . \\
6\end{array}$ & 0.58 & 5.16 & $\begin{array}{c}3.5 \\
3\end{array}$ & 5.12 & $\begin{array}{c}99 . \\
3\end{array}$ & 0.76 \\
\hline DCM & 220 & 11.3 & 1.15 & 4.15 & 7.84 & $\begin{array}{c}97 . \\
0\end{array}$ & 0.50 & 6.14 & $\begin{array}{c}4.4 \\
9\end{array}$ & 6.05 & $\begin{array}{c}98 . \\
5\end{array}$ & 0.64 \\
\hline $\begin{array}{c}\text { Propan } \\
\text { ol }\end{array}$ & $\begin{array}{c}0.3 \\
1\end{array}$ & 9.88 & 1.08 & 4.07 & 0.35 & 4.6 & 11.20 & 5.74 & 4.4 & 0.51 & 8.9 & 7.63 \\
\hline $\begin{array}{c}\text { Aceton } \\
e\end{array}$ & $\begin{array}{c}2.2 \\
8\end{array}$ & 10.2 & 1.09 & 4.10 & 2.00 & $\begin{array}{c}26 . \\
0\end{array}$ & 1.95 & 5.84 & $\begin{array}{c}4.4 \\
3\end{array}$ & 2.42 & $\begin{array}{c}41 . \\
5\end{array}$ & 1.60 \\
\hline
\end{tabular}

Table 5: Mass-transfer coefficients and $R_{L}$ values according to the Billet-Schultes + Piché et al. and Mackowiak theories using DEHA.

\begin{tabular}{|c|c|c|c|c|c|c|c|c|c|c|c|c|}
\hline \multirow[b]{3}{*}{ VOC } & \multicolumn{2}{|c|}{ Properties } & \multicolumn{5}{|c|}{ Billet-Schultes + Piché et al theories } & \multicolumn{5}{|c|}{ Mackowiak theory } \\
\hline & $H$ & $\begin{array}{c}10^{10 x} \\
D_{L}\end{array}$ & $\begin{array}{c}10^{5} x \\
k_{L}\end{array}$ & $\begin{array}{c}10^{2} \times k \\
G\end{array}$ & $\begin{array}{c}10^{3} \times K_{L} \\
a^{0}\end{array}$ & $R_{L}$ & $\begin{array}{c}H U T \\
O L\end{array}$ & $\begin{array}{c}10^{3} \times k_{L} \\
a^{\circ}\end{array}$ & $\underset{\circ}{k_{G} a}$ & $\begin{array}{c}10^{3} \times K_{L} \\
a^{0}\end{array}$ & $R_{L}$ & $\begin{array}{c}H U T \\
O L\end{array}$ \\
\hline & $\begin{array}{c}\mathrm{Pa} \\
\mathrm{m}^{3} \\
\mathrm{~mol}_{-1}\end{array}$ & $\mathrm{~m}^{2} \mathrm{~s}^{-1}$ & $\mathrm{~m} \mathrm{~s}^{-1}$ & $\mathrm{~m} \mathrm{~s}^{-1}$ & $\mathrm{~s}^{-1}$ & $\%$ & $\mathrm{~m}$ & $\mathrm{~s}^{-1}$ & $\mathrm{~s}^{-1}$ & $\mathrm{~s}^{-1}$ & $\%$ & $\mathrm{~m}$ \\
\hline $\begin{array}{l}\text { Toluen } \\
\text { e }\end{array}$ & $\begin{array}{c}0.7 \\
6\end{array}$ & 1.90 & 3.12 & 3.42 & 0.51 & $\begin{array}{c}25 \\
5\end{array}$ & 7.57 & 4.98 & $\begin{array}{c}8.5 \\
9\end{array}$ & 1.74 & $\begin{array}{c}35 . \\
0\end{array}$ & 2.23 \\
\hline DCM & $\begin{array}{c}4.7 \\
3\end{array}$ & 2.71 & 3.73 & 4.29 & 1.66 & $\begin{array}{c}69 . \\
1\end{array}$ & 2.34 & 5.94 & $\begin{array}{c}11 . \\
0\end{array}$ & 4.65 & $\begin{array}{c}78 . \\
2\end{array}$ & 0.84 \\
\hline $\begin{array}{c}\text { Propan } \\
\text { ol }\end{array}$ & $\begin{array}{c}6.5 \\
7\end{array}$ & 2.37 & 3.49 & 4.2 & 1.72 & $\begin{array}{c}76 . \\
4\end{array}$ & 2.26 & 5.56 & $\begin{array}{c}10 . \\
7\end{array}$ & 4.66 & $\begin{array}{c}83 . \\
8\end{array}$ & 0.83 \\
\hline $\begin{array}{c}\text { Aceton } \\
e\end{array}$ & $\begin{array}{c}12 . \\
7\end{array}$ & 2.45 & 3.55 & 4.23 & 1.97 & $\begin{array}{c}86 . \\
1\end{array}$ & 1.97 & 5.65 & $\begin{array}{c}10 . \\
8\end{array}$ & 5.13 & $\begin{array}{c}90 . \\
9\end{array}$ & 0.76 \\
\hline
\end{tabular}

Table 6: Mass-transfer coefficients and $R_{L}$ values according to the Billet-Schultes + Piché et al. and Mackowiak theories using PDMS 50.

\begin{tabular}{|c|c|c|c|c|c|c|c|c|c|c|c|c|}
\hline \multirow[b]{3}{*}{ VOC } & \multicolumn{2}{|c|}{ Properties } & \multicolumn{5}{|c|}{ Billet-Schultes + Piché et al theories } & \multicolumn{5}{|c|}{ Mackowiak theory } \\
\hline & $H$ & $\begin{array}{c}10^{10 x} \\
D_{L}\end{array}$ & $\begin{array}{c}10^{5 x} \\
k_{L}\end{array}$ & $\begin{array}{c}10^{2} \times k \\
G\end{array}$ & $\begin{array}{c}10^{3} \times K_{L} \\
a^{\circ}\end{array}$ & $R_{L}$ & $\begin{array}{c}H U T \\
\text { OL }\end{array}$ & $\begin{array}{c}10^{3} \times k_{L} \\
a^{\circ}\end{array}$ & $\underset{\circ}{k_{G} a}$ & $\begin{array}{c}10^{3} \times K_{L} \\
a^{0}\end{array}$ & $R_{L}$ & $\begin{array}{c}\text { HUT } \\
\text { OL }\end{array}$ \\
\hline & $\begin{array}{c}\mathrm{Pa} \\
\mathrm{m}^{3} \\
\mathrm{~mol}^{-} \\
1\end{array}$ & $\mathrm{~m}^{2} \mathrm{~s}^{-1}$ & $\mathrm{~m} \mathrm{~s}^{-1}$ & $\mathrm{~m} \mathrm{~s}^{-1}$ & $\mathrm{~s}^{-1}$ & $\%$ & $\mathrm{~m}$ & $\mathrm{~s}^{-1}$ & $\mathrm{~s}^{-1}$ & $\mathrm{~s}^{-1}$ & $\%$ & $\mathrm{~m}$ \\
\hline $\begin{array}{c}\text { Toluen } \\
\text { e }\end{array}$ & 1.36 & 1.40 & 2.15 & 3.53 & 0.63 & $\begin{array}{c}47 . \\
8\end{array}$ & 6.20 & 5.52 & $\begin{array}{c}11 . \\
8\end{array}$ & 3.00 & $\begin{array}{c}54 . \\
4\end{array}$ & 1.30 \\
\hline $\mathrm{DCM}$ & $\begin{array}{c}22.0 \\
1\end{array}$ & 1.99 & 2.57 & 4.44 & 1.47 & $\begin{array}{c}94 . \\
0\end{array}$ & 2.64 & 6.58 & $\begin{array}{c}15 . \\
1\end{array}$ & 6.28 & $\begin{array}{c}95 . \\
4\end{array}$ & 0.62 \\
\hline
\end{tabular}




\begin{tabular}{|c|c|c|c|c|c|c|c|c|c|c|c|c|}
\hline $\begin{array}{c}\text { Propan } \\
\text { ol }\end{array}$ & $\begin{array}{c}21.4 \\
2\end{array}$ & 1.74 & 2.40 & 4.35 & 1.38 & $\begin{array}{c}94 . \\
1\end{array}$ & 2.82 & 6.16 & $\begin{array}{c}14 . \\
8\end{array}$ & 5.88 & $\begin{array}{c}95 . \\
5\end{array}$ & 0.66 \\
\hline $\begin{array}{c}\text { Aceton } \\
e\end{array}$ & $\begin{array}{c}52.9 \\
7\end{array}$ & 1.80 & 2.44 & 4.38 & 1.45 & $\begin{array}{c}97 . \\
5\end{array}$ & 2.68 & 6.26 & $\begin{array}{c}14 . \\
9\end{array}$ & 6.14 & $\begin{array}{c}98 . \\
1\end{array}$ & 0.63 \\
\hline
\end{tabular}

The overall volumetric liquid-phase mass-transfer coefficients $\left(K_{\llcorner} a^{\circ}\right)$ obtained for water are close using both Billet-Schultes and Mackowiak theories, with an Average Relative Error (ARE) of 27\% considering the four VOC (Table 4). As expected, $K_{L} a^{\circ}$ and the percentage of resistance in the liquid phase $\left(R_{L}\right)$ both decreased when the affinity between the VOC and the solvent (lower $H$ value) increases $[3,15]$ :

$R_{L}=\left(1+\frac{R T k_{L} a^{\circ}}{H k_{G} a^{\circ}}\right)^{-1}$

Eq. 27.

$R_{L}$ allows to assess the weight of the liquid-phase resistance compared to the gas-phase resistance. Depending on the solute, $H T U_{O L}$ for water (Eq. 2) varies from half a meter to more than $10 \mathrm{~m}$ (Table 4). Considering DEHA and PDMS, the disagreement between both theories is more important (Tables 5 and 6). Indeed, the Mackowiak theory predicted $K_{L} a^{\circ}$ values around 2.9 (DEHA) and 4.4 (PDMS 50) times higher than the one calculated with the Billet-Schultes theory coupled to the Piché et al. theory to calculate $a^{\circ}$. The liquid-film mass-transfer coefficient $\left(k_{L}\right)$ calculated with the Billet-Schultes theory were three to five times lower than the one predicted for water, which was consistent with an expected slower solute transport in viscous organic solvents. On the contrary, the Mackowiak correlation predicted $k_{L} a^{\circ}$ values slightly lower for DEHA (3-4\%) and slightly higher for PDMS (6-7\%) than the one found using water. The Billet-Schultes theory predicted $k_{G}$ values consistent between the three solvents whereas the Mackowiak theory predicted inconsistent $k_{G} a^{\circ}$ values, from two to three times larger with PDMS and DEHA than with water. Such a large sensitivity of $k_{G} a^{\circ}$ to the solvent properties was unexpected since $k_{G}$ should be uninfluenced by the solvent selected.

In the Mackowiak theory, $a^{\circ}$ cannot be calculated separately. Thus, the discrepancies observed using this theory might be due to a severe overestimation of the interfacial area, such as the Billet-Schultes theory 
using Eq. 19 (section 3.1.2). Thus, the $K_{L} a^{\circ}$ values which would have been calculated using only the BilletSchultes theory (without correcting the interfacial area by the Piché et al. correlation), and using the Mackowiak theory was particularly close, with ARE of $9 \%$ for DEHA and $27 \%$ for PDMS 50 . The high sensitivity of $a^{\circ}$ to the solvent properties of the Mackowiak theory and of Eq. 19 is mainly due to an important influence of the liquid surface tension, which tends to overestimate the packing wetting without taking the larger viscosity into account in the balance. Their high discrepancies are justified by the fact that these correlations were established using narrow liquid kinematic viscosity ranges, which include water but not DEHA and PDMS 50.

Nonetheless, the Billet-Schultes correlation (Eqs 17 and 18) coupled to the Piché et al. correlation should be adequate to calculate respectively $k_{L} / k_{G}$ (section 2.4.1) and $a^{\circ}$ (sections 2.4 .3 and 3.1.2) according to their validity ranges. This conclusion was supported by the toluene $K_{L} a^{\circ}$ values in DEHA and PDMS 50, equal respectively to $0.51 \times 10^{-3}$ and $0.63 \times 10^{-3} \mathrm{~s}^{-1}$, which were in good agreement with the values measured by Heymes et al. (2006) and Guillerm et al. (2016) [12, 17]. 


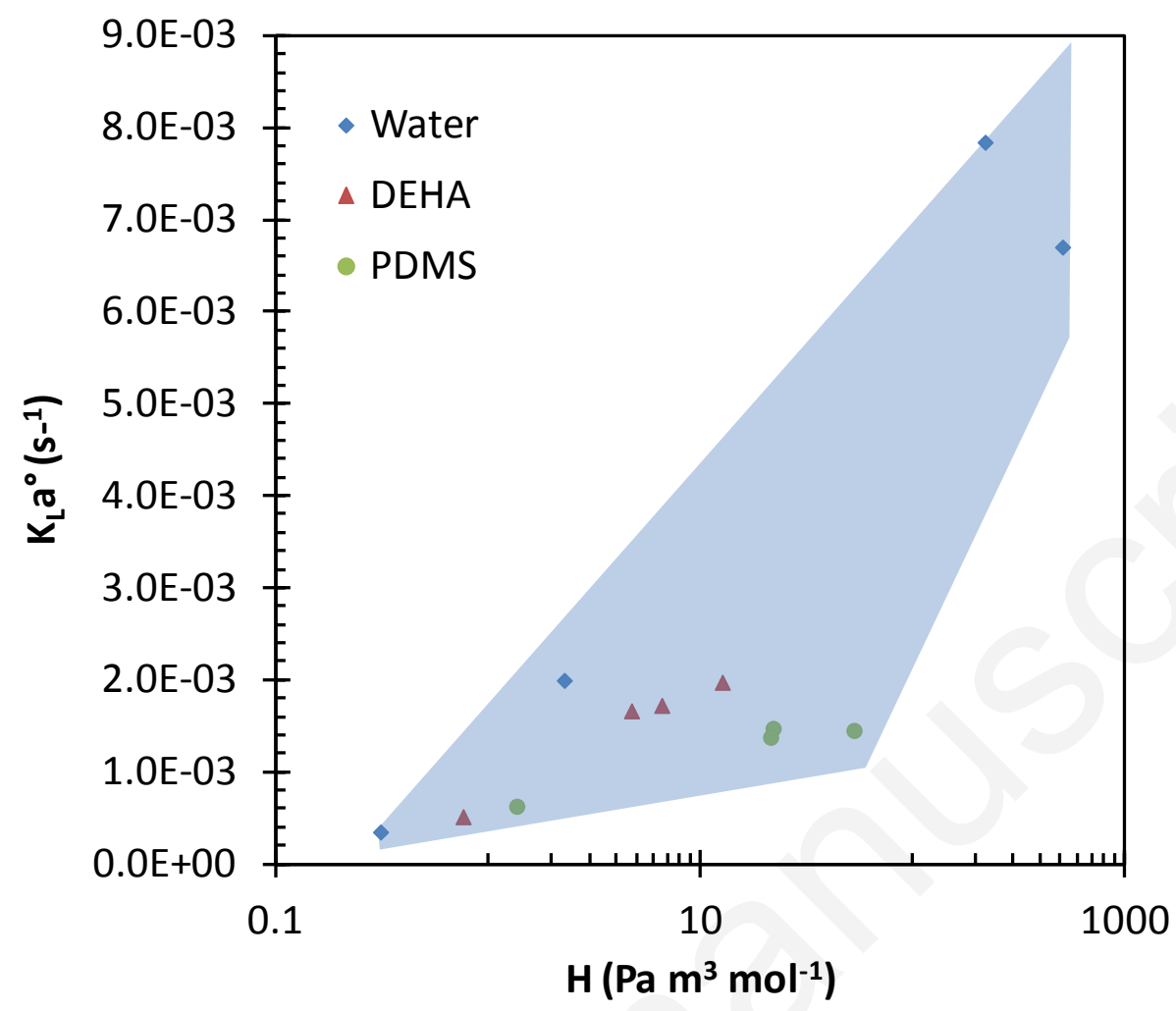

Figure 1: Correlation between $\mathrm{K}_{\mathrm{L}} \mathrm{a}^{\circ}\left(\mathrm{s}^{-1}\right)$ and the Henry's law constants $\left(\mathrm{Pa} \mathrm{m}^{3} \mathrm{~mol}^{-1}\right)$.

Heymes et al. (2006) neglected the gas-phase resistance (i.e. they assume $k_{L} a^{\circ}=K_{L} a^{\circ}$ ) which leads to an erroneous opposite conclusion about the accuracy of the Billet-Schultes theory applied to viscous solvents [17]. Indeed, the percentage of the liquid resistance vary from 25 to $98 \%$ for DEHA and PDMS 50 (Tables 5 and 6). It emphasizes that except for a few cases, the gas-side resistance should never be neglected, especially for toluene which possess a high affinity for these solvents. Finally, $K_{L} a^{\circ}$ is poorly sensitive to the solvent properties, but increases significantly with the Henry's law constant. Indeed, the $K_{L} a^{\circ}$ values computed for different solvent/solute couples remains in a narrow window (Fig. 1). 


\subsection{Removal efficiencies determination}
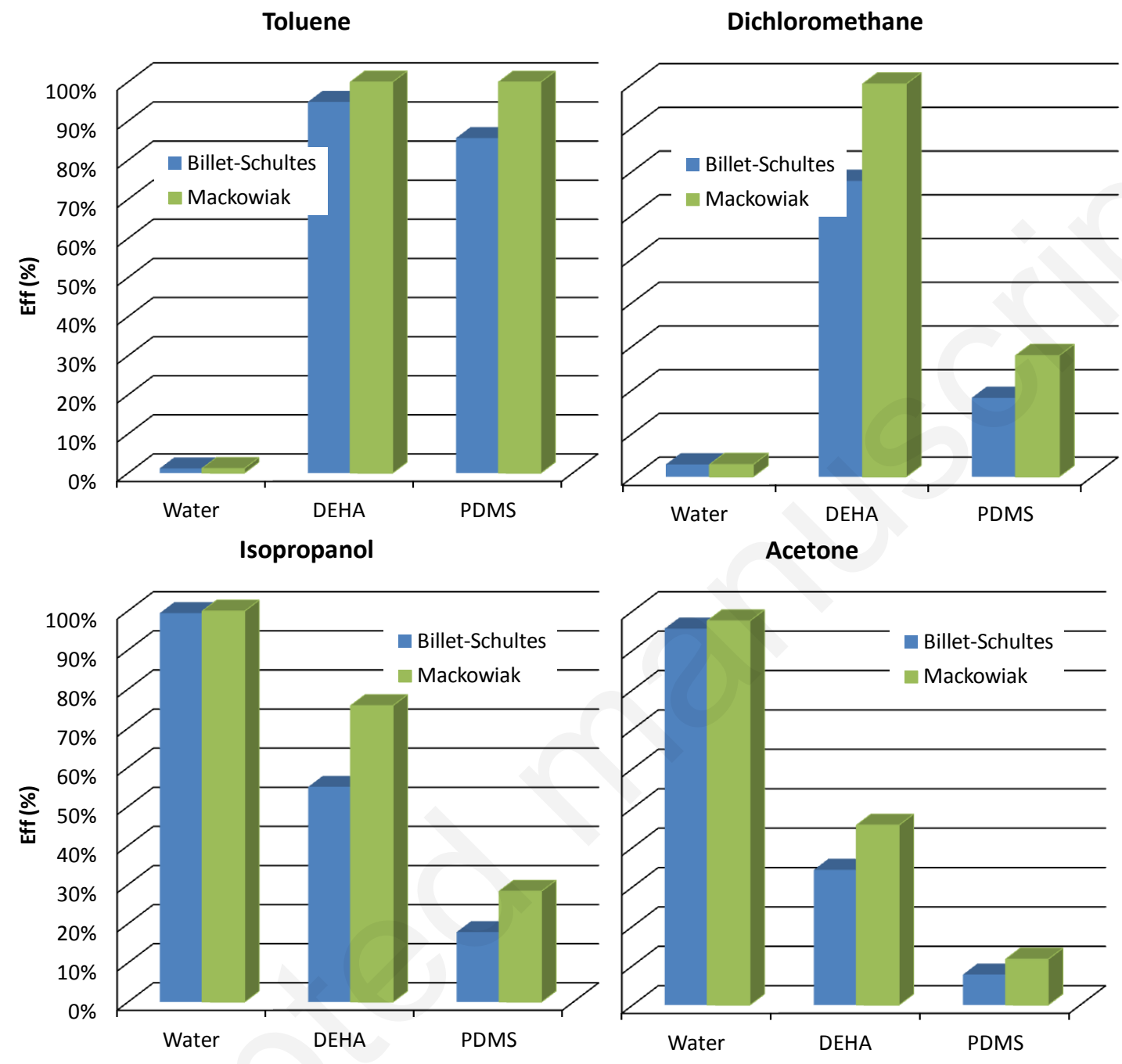

Figure 2: Removal efficiencies according to the Billet-Schultes and Mackowiak theories.

The removal efficiencies, deduced from Eq. 2, varied from $1 \%$ up to $95 \%$ depending on the VOC/solvents affinities (Figures 2). The toluene removal efficiencies in DEHA and PDMS 50 (> 80\%) were in agreement with the available experimental data at similar conditions, which strengthens the reliability of these simulations $[12,16,17]$. The influence of the considered mass-transfer theory remained limited, even with high discrepancies for DEHA and PDMS 50 (section 3.2). However, the removal efficiency was strongly correlated to the Henry's law constant. Indeed, Fig. 3 represents the evolution of the removal efficiency for the different VOC/solvent couples vs. the corresponding Henry's law constant for the two 
considered mass-transfer theories. The orange thin shape highlighted that the removal efficiency poorly depends on the solvent and mass-transfer theory choice for a given value of $H$. In fact, Eff is mostly sensitive to the $\mathrm{VOC} /$ solvent affinity through the absorption rate $A$ (Eq. 2), more than to the masstransfer coefficient $K_{\llcorner} a^{\circ}$. It highlights the robustness of the removal efficiencies prediction.

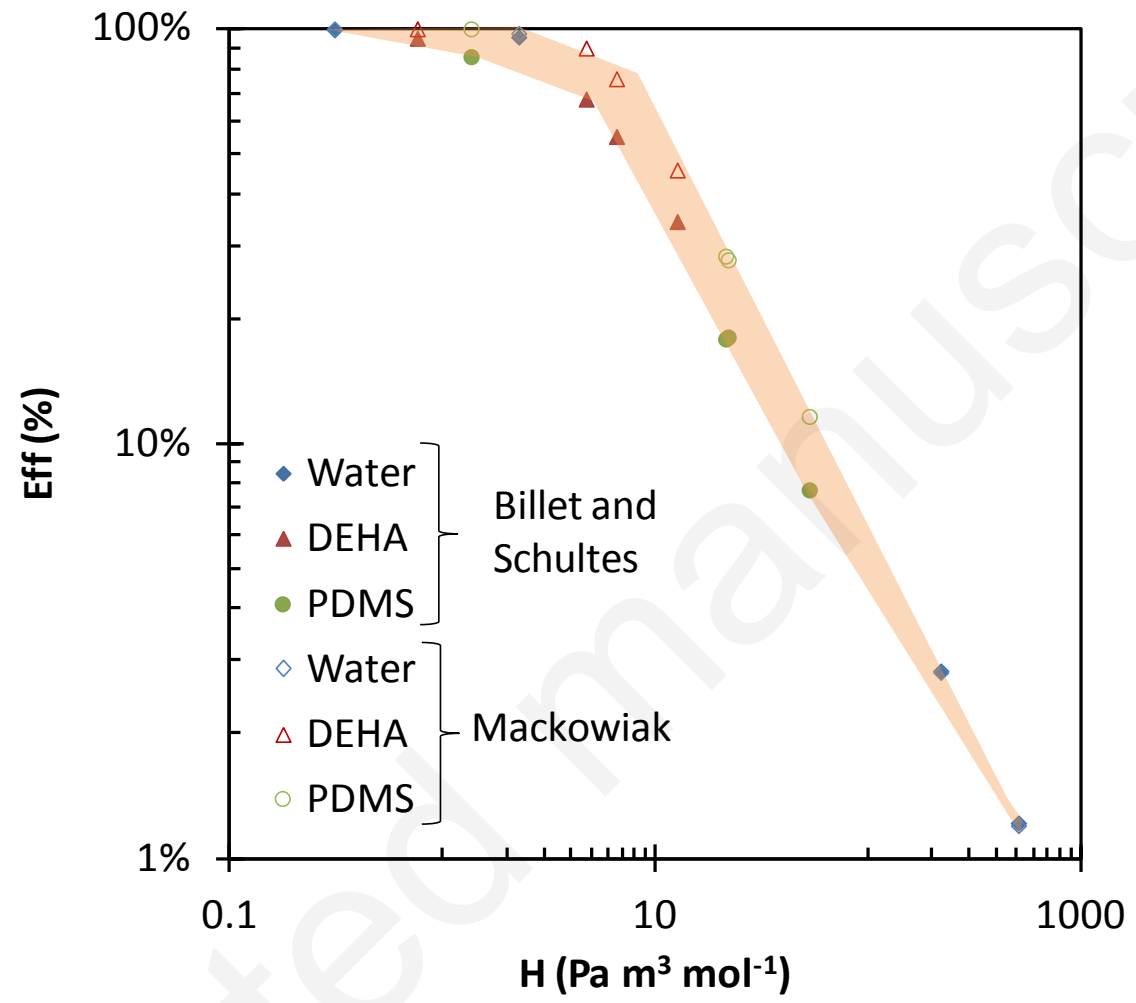

Figure 3: Correlation between the simulated removal efficiencies (\%) and the Henry's law constants $\left(\mathrm{Pa} \mathrm{m}^{3} \mathrm{~mol}^{-1}\right)$.

Therefore, according to Fig. 3, a Henry's law constant roughly lower than $2 \mathrm{~Pa} \mathrm{~m}^{3} \mathrm{~mol}^{-1}$ is necessary to reach Eff larger than $90 \%$ (for $L / G=2$ and $Z=3 \mathrm{~m}$ ), corresponding to an absorption rate $A$ larger than 23, independently of the solvent properties and mass-transfer theory. Thus, Eff can be quickly estimated for other operating conditions according to Eq. 2, assuming a pessimistic/optimistic $K_{L} a^{\circ}$ value deduced from the Fig. 1. For example, a packed column of approximately $8 \mathrm{~m}$ height would be necessary to reach a removal efficiency of $90 \%$ with $L / G=2$ for the removal of a compound with $H$ around $5 \mathrm{~Pa} \mathrm{~m}^{3} \mathrm{~mol}^{-1}$ (considering $K_{L} a^{\circ} \approx 2 \times 10^{-3} \mathrm{~s}^{-1}$ ). 
Therefore, even being less selective than water, the considered heavy solvents, particularly PDMS 50, would be ineffective to treat at atmospheric pressure some VOC such as isopropanol $(E f f<70 \%)$ or acetone $(E f f<40 \%)$ and in a lower extent DCM (Eff < 30\% in PDMS 50) (Fig. 2). The removal efficiencies obtained for isopropanol and acetone in DEHA and PDMS 50 are even lower than in water, which is particularly effective to treat these two polar compounds (Eff $>90 \%)$. Consequently, a combination of two scrubbers working with water and an organic solvent is a feasible option to target a large panel of VOC.

\subsection{Sensitivity to the liquid diffusion coefficients analysis}

Through the $H$ value, Eff is mainly sensitive to the VOC/solvent affinity (Fig. 3). Indeed, the solvent properties and the mass-transfer coefficient prediction poorly affect the removal efficiency determination. Thus, even using viscous solvents, which hinder solute diffusion in the liquid phase, the mass-transfer rate was satisfactory (section 3.3). However, these conclusions were based on masstransfer coefficients evaluated using probably slightly underestimated liquid diffusion coefficient calculated with the Wilke-Chang correlation [3]. The experimental determination of the diffusion coefficient is rather time consuming and requires expensive experimental devices.

To assess the sensitivity of the simulations to $D_{L}$, the removal efficiencies were recalculated for DEHA and PDMS 50 taking pessimistic/optimistic scenario into account, i.e. diffusion coefficients divided and multiplied by 1 order of magnitude (Table 7). A moderate sensitivity of Eff to $D_{L}$ is observed. $D_{L}$ influences Eff determination through the liquid-film mass-transfer coefficient calculation. In agreement with the Higbie penetration theory, both Billet-Schultes and Mackowiak theories assumed a square-root dependence of $k_{L}$ on $D_{L}$. Therefore, $K_{L} a^{\circ}$, and even more Eff, are poorly sensitive to $D_{L}$. Therefore, the inaccuracy of the typical $D_{L}$ correlation might be less significant than the inherent Henry's law constant experimental uncertainties. Consequently, the design of packed columns fed by viscous solvents with a 
sufficient confidence level is possible using the Billet-Schultes theory for $k_{L}$ and $k_{G}$ calculations, and using the Piché et al. theory for $a^{\circ}$ calculation. The loading and flooding points and the liquid hold up can be previously determined using the Billet-Schultes theory.

Table 7 : Removal efficiencies (based on the Billet-Schultes theory) obtained using DEHA and PDMS 50 considering $D_{L}$ (Table 3 ), and $D_{L}$ divided/multiplicated by 1 order of magnitude (sensitivity analysis).

\begin{tabular}{|ccccccccc}
\hline & \multicolumn{9}{c}{ DEHA } \\
\hline & Toluene & DCM & Isopropanol & Acetone & Toluene & DCM & Isopropanol & Acetone \\
Eff $(\%)$ & 94.9 & 67.6 & 55.0 & 34.3 & 85.7 & 18.1 & 17.9 & 7.7 \\
Eff $(\%)$ with $D_{L} / 10$ & 85.8 & 42.4 & 32.0 & 18.7 & 63.3 & 8.5 & 8.3 & 3.5 \\
Eff (\%) with $D_{L} \times 10$ & 97.2 & 82.8 & 71.2 & 45.2 & 94.0 & 26.2 & 26.6 & 11.3 \\
\hline
\end{tabular}

\subsection{Potential improvements}

To improve the removal efficiency, several options can be considered:

- Working at high pressure instead of the atmospheric pressure. In that case, the Henry's law cannot be valid anymore. Furthermore, the correlations for the design of packed column are usually developed at low or moderate pressure and might be invalid at high pressures. Experimental studies with packed column fed by viscous solvents at high pressure should be undertaken to confirm the potential of this option.

- Increasing the $L / G$ ratio affecting directly the pressure drop and the functioning costs. The benefit of this solution seems limited. For example, for $L / G=6$ (instead of 2 in this study), the DCM removal efficiency in PDMS with the same column would increase from $18.1 \%$ to $23.9 \%$ only, whereas the linear pressure drop would increase from 416 to nearly $700 \mathrm{~Pa} \mathrm{~m}^{-1}$.

- Increasing the contact time through the column height affecting again the pressure drop and the investment costs (an example is given in the section 3.3). 
- Working with a water/organic solvents mixture to benefit from the affinity of both solvents for various VOC $[39,40]$. However, a simulation of such mixtures is impossible due to the ignorance of the surface tension, viscosity, liquid diffusion coefficients, etc.

- Combining two scrubbers in series since the most hydrophobic compounds are those which are poorly removed by organic solvents. In that case, some compounds, such as dichloromethane in PDMS 50 will be still poorly absorbed. For example, for a desired removal efficiency of $90 \%$, a minimal $L / G$ ratio of 6.5 would be necessary at atmospheric pressure. Applying an effective $L / G$ ratio $=9.3\left(F_{L}\right.$ $\left.=50 \mathrm{~m}^{3} \mathrm{~h}^{-1}\right)$, the contactor height would be equal to $51 \mathrm{~m}\left(D_{c o l}=1.14 \mathrm{~m}\right)$ for a total pressure drop of $18.5 \mathrm{kPa}$. Using the DEHA instead, a column of $8.5 \mathrm{~m}$ of height should be implemented for a $L / G$ ratio of 2 and a total pressure drop of almost $3 \mathrm{kPa}$. Thus, in some cases, effective absorption of VOC in organic solvents would be complicated to achieve.

\section{Conclusion and perspectives}

Hydrodynamics and mass-transfer performances of a packed column for VOC absorption in heavy solvents (PDMS 50 and DEHA) were assessed using several theories. Reliable values of the hydrodynamic variables were obtained using the Billet-Schultes theory. This theory seemed to also predict accurate values of the liquid and gas-film mass-transfer coefficients by comparison to experimental data [12, 16, 17]. However, this theory is unable to predict the interfacial area for such viscous solvents. Thus, the Piché et al. correlation was recommended instead. The linear pressure drop obtained with these solvents remained reasonable. Removal efficiencies larger than $90 \%$ were predicted for toluene absorption in the organic solvents with a $3 \mathrm{~m}$ column operated at the atmospheric pressure and with a $L / G$ ratio around 2 . However, PDMS 50 and DEHA are ineffective to treat in these conditions some VOC such as isopropanol $(E f f<70 \%)$ or acetone $(E f f<40 \%)$ and in a lower extent dichloromethane $(E f f<30 \%$ in PDMS 50$)$. 
The high sensitivity of the removal efficiency to the VOC/solvent affinity reveals that the removal of VOC, with $H$ roughly higher than $2 \mathrm{~Pa} \mathrm{~m}^{3} \mathrm{~mol}^{-1}$ (acetone, isopropanol and dichloromethane using PDMS), is disappointing. The predictions of these simulations were in agreement with experimental data $[12,17]$. Thus, it emphasizes that even if heavy solvents are less selective than water, they can hardly be used to target a large panel of VOC. Besides, the toluene choice as a model VOC in many studies focused on the selection of heavy solvents is questionable. This compound has a high affinity for this kind of solvents and is not the most representative. Acetone, isopropanol and dichloromethane are undoubtedly more challenging compounds for this application.

A combination of two scrubbers in series, working with water and an organic solvent could be a feasible and cost-effective solution to target a rather large panel of VOC. Recent investigations focused on the development of tunable ionic liquid can be a potential answer since a lower selectivity might be expected compared to DEHA and PDMS 50 [41].

The regeneration of the scrubbing liquid, which must be recycled to guaranty the economic viability of the process, is a crucial issue. Water can be regenerated by a chemical reaction (oxidation using ozone or an advanced oxidation processes) [42]. Some separation unit operation such as the stripping or the pervaporation can be investigated for the solvent recovery but they are energy consuming [43-48]. An alternative would be to regenerate them by biodegradation for non biodegradable solvents such as PDMS or some ionic liquids [49].

\section{Acknowledgments}

The research leading to these results has received funding from the European Union's Seventh Framework Program (FP7/2007-2013) managed by REA-Research Executive Agency (http://ec.europa.eu/research/rea) under grant agreement no 315250 (CARVOC program). 


\section{References}

[1] S. Revah, J.M. Morgan-Sagastume, in Methods of odor and VOC control, pp. 29-63, Springer, (2005).

[2] M. Schlegelmilch, J. Streese, R. Stegmann, Waste Management, 25 (2005) 928-939.

[3] P.-F. Biard, A. Coudon, A. Couvert, S. Giraudet, Chem. Eng. J., 290 (2016) 302-311.

[4] G. Darracq, A. Couvert, C. Couriol, A. Amrane, P. Le Cloirec, Can. J. Chem. Eng., 88 (2010) 655-660.

[5] G. Darracq, A. Couvert, C. Couriol, A. Amrane, D. Thomas, E. Dumont, Y. Andres, P. Le Cloirec, Journal of Chemical Technology \& Biotechnology, 85 (2010) 309-313.

[6] F. Heymes, P. Manno-Demoustier, F. Charbit, J.L. Fanlo, P. Moulin, Chem. Eng. J., 115 (2006) 225-231.

[7] S. Guihéneuf, A.S.R. Castillo, L. Paquin, P.-F. Biard, A. Couvert, A. Amrane, in Absorption of Hydrophobic Volatile Organic Compounds in Ionic Liquids and Their Biodegradation in Multiphase Systems, pp. 305-337, Springer, (2014).

[8] D. Bourgois, D. Thomas, J.L. Fanlo, J. Vanderschuren, Journal of Chemical Engineering Data, 51 (2006) 1212-1215.

[9] R. Hadjoudj, H. Monnier, C. Roizard, F. Lapicque, Ind. Eng. Chem. Res., 43 (2004) 2238-2246.

[10] M.J. Patel, S.C. Popat, M.A. Deshusses, Chem. Eng. J., 310 (2016) 72-78.

[11] H. Wu, Separation Science and Technology, 50 (2015) 1294-1301. 
[12] M. Guillerm, A. Couvert, A. Amrane, E. Norrant, N. Lesage, É. Dumont, Chem. Eng. Res. Des., 109 (2016) 32-40.

[13] M. Guillerm, A. Couvert, A. Amrane, É. Dumont, E. Norrant, N. Lesage, C. Juery, J. Chem. Technol. Biotechnol., 95 (2015) 1923-1927.

[14] H. Chen, B. Barna, T. Rogers, D. Shonnard, Clean Products and Processes, 3 (2001) 290-302.

[15] E. Dumont, G. Darracq, A. Couvert, C. Couriol, A. Amrane, D. Thomas, Y. Andrès, P. Le Cloirec, Chem. Eng. J., 221 (2013) 308-314.

[16] G. Darracq, PhD thesis ENSCR-005, Rennes (2011).

[17] F. Heymes, P.M. Demoustier, F. Charbit, J.L. Fanlo, P. Moulin, Chem. Eng. Sci., 61 (2006) 5094-5106.

[18] B. Ozturk, C. Kuru, H. Aykac, S. Kaya, Sep. Purif. Technol., 153 (2015) 1-6.

[19] J. Xu, R. Li, L. Wang, J. Li, X. Sun, Sep. Purif. Technol., 68 (2009) 75-82.

[20] J. Sangster, Journal of Physical and Chemical Reference Data, 18 (1989) 1111-1229.

[21] J. Mackowiak, Fluid Dynamics of Packed Columns - Principles of the Fluid Dynamic Design of Columns for Gas/Liquid and Liquid/Liquid Systems, Springer, Berlin Heidelberg (2010).

[22] D. Bourgois, J. Vanderschuren, D. Thomas, Chemical Engineering \& Processing: Process Intensification, 47 (2008) 1363-1370.

[23] R. Hadjoudj, H. Monnier, C. Roizard, F. Lapicque, Chemical Engineering and Processing: Process Intensification, 47 (2008) 1478-1483.

[24] R. Billet, M. Schultes, Chem. Eng. Res. Des., 77 (1999) 498-504.

[25] M. Roustan, Transferts gaz-liquide dans les procédés de traitement des eaux et des effluents gazeux, Lavoisier, Paris (2003). 
[26] S. Piché, B.P. Grandjean, I. Iliuta, F. Larachi, Environ. Sci. Technol., 35 (2001) 4817-4822.

[27] S. Piché, B.P. Grandjean, F. Larachi, Ind. Eng. Chem. Res., 41 (2002) 4911-4920.

[28] R. Billet, M. Schultes, Chem. Eng. Technol., 16 (1993) 1-9.

[29] R. Billet, M. Schultes, Chem. Eng. Technol., 14 (1991) 89-95.

[30] R. Billet, M. Schultes, Chem. Eng. Technol., 16 (1993) 370-375.

[31] R. Billet, M. Schultes, Chem. Eng. Technol., 18 (1995) 371-379.

[32] J. Maćkowiak, Chem. Eng. Res. Des., 89 (2011) 1308-1320.

[33] J. Maćkowiak, Chem. Eng. Res. Des., 99 (2015) 28-42.

[34] S. Piché, F. Larachi, B. Grandjean, Chem. Eng. Res. Des., 79 (2001) 71-80.

[35] S. Piché, F. Larachi, B.P. Grandjean, Ind. Eng. Chem. Res., 40 (2001) 476-487.

[36] S. Piché, F. Larachi, B.P. Grandjean, Chem. Eng. Technol., 24 (2001) 373-380.

[37] S.R. Piché, F. Larachi, B. Grandjean, Can. J. Chem. Eng., 79 (2001) 584-594.

[38] H. Onda, H. Takeuchi, Y. Koyama, Kagaku Kogaku, 31 (1967) 126-133.

[39] E. Dumont, G. Darracq, A. Couvert, C. Couriol, A. Amrane, D. Thomas, Y. Andrès, P. Le Cloirec, Chem. Eng. J., 168 (2011) 241-248.

[40] E. Dumont, A. Couvert, A. Amrane, C. Couriol, G. Darracq, P. Le Cloirec, Chem. Eng. J., 287 (2016) 205-216.

[41] A.S. Rodriguez Castillo, S. Guihéneuf, R. Le Guével, P.-F. Biard, L. Paquin, A. Amrane, A. Couvert, Journal of hazardous materials, 307 (2016) 221-230. 
[42] P.-F. Biard, A. Couvert, C. Renner, J.-P. Levasseur, Chemosphere, 85 (2011) 1122-1129.

[43] E. Chabanon, B. Belaissaoui, E. Favre, Journal of Membrane Science, 459 (2014) 52-61.

[44] N.L. Mai, K. Ahn, Y.-M. Koo, Process Biochemistry, 49 (2014) 872-881.

[45] B.A. Oyenekan, G.T. Rochelle, Ind. Eng. Chem. Res., 45 (2006) 2457-2464.

[46] F. Heymes, P.M. Demoustier, F. Charbit, J. Fanlo, P. Moulin, Journal of Membrane Science, 284 (2006) $145-154$.

[47] F. Heymes, P.M. Demoustier, F. Charbit, J.-L. Fanlo, P. Moulin, Chem. Eng. Sci., 62 (2007) 2576-2589.

[48] K.K. Sirkar, Ind. Eng. Chem. Res., 47 (2008) 5250-5266.

[49] G. Darracq, A. Couvert, C. Couriol, A. Amrane, P. Le Cloirec, Water Science and Technology, 59 (2009) 1315. 